\title{
Visual evoked potentials in rotogravure printers exposed to toluene
}

\author{
P Urban, E Lukáš
}

\begin{abstract}
Visual evoked potentials (VEPs) from stimulation by checkerboard pattern reversal were examined in 54 rotogravure printers exposed to toluene (all men, aged $22-64$ years, duration of exposure 1-41 years). A control group consisted of 46 subjects ( 23 men and 23 women; aged 22-54 years). Compared with controls the exposed group showed more frequent responses with reduced reproducibility or absence of some waves, or both; the mean P1 wave latency was prolonged and mean amplitudes N1P1 and P1N2 were reduced. The VEPs were abnormal in $24 \%$ of workers. The frequency of abnormal VEPs correlated positively with the duration of exposure to toluene and also with the degree of alcohol drinking. No association was found between measurements of VEP and electroencephalogram (EEG) or electromyogram (EMG) examinations. A VEP measurement was made in $78 \%$ of the exposed workers two years after the first examination. No statistically significant difference between the two results was found. This suggests a marked stability of the observed VEP changes. These changes can be interpreted as a subclinical sign of dysfunction of the central nervous system (CNS) related to exposure to toluene and also to alcohol consumption.
\end{abstract}

Visual evoked potentials (VEPs) were used by Seppäläinen $e t$ al ${ }^{1}$ and other authors ${ }^{2-5}$ to study the neurotoxic effect of organic solvents on workers exposed to these compounds. They described VEP changes in groups of exposed workers compared with control groups. The pattern of latency and amplitude changes of the evoked response, however, was not uniform between the studies. This may be due to differences in the method of VEP measurement used (for example, diffuse $v$ structured stimuli) or to differenes in exposure (type of solvents, intensity of exposure).

Centre of Industrial Hygiene and Occupational Diseases of the Institute of Hygiene and Epidemiology, Prague, Czechoslovakia

P Urban, E Lukáš
The aim of our study was to detect VEP changes in a group of rotogravure printers with an intensive exposure to toluene. As well as group evaluation we assessed the results individually and also the dynamics of changes by means of a second examination two years later.

\section{Subjects and methods EXPOSED GROUP}

The exposed group consisted of 54 rotogravure printers who met the inclusion criteria: (1) normal visual acuity (natural or corrected) and (2) absence of an illness known or assumed to influence VEPs. All 54 workers were men, mean age 38 (range 22-54) years at the time of the first VEP examination. The mean duration of their work in the plant was 10 (141) years. Table 1 gives the distribution of the group into subgroups according to the duration of exposure.

We estimated the alcohol drinking habits of the workers on the basis of their autoanamnestic data. Table 2 presents the results (in view of the general tendency of people to understimate their alcohol habits we assume it to be worse in reality then stated).

Chromatographic analysis showed that the technical toluene used in the plant contained $98.4 \%$ toluene. The degree of exposure was documented in three ways. Firstly, toluene concentration in the workers' breathing zone air was measured. The mean value for the period $1977-87$ was about $2000 \mathrm{mg} / \mathrm{m}^{3}$. Secondly hippuric acid concentration in urine sampled at the end of a shift was determined as a biological test for toluene. The mean value for the same period was about $44 \mathrm{mmol} / 1$ (after correction to the standard density of urine, $1020 \mathrm{~g} / \mathrm{l}$ ). Thirdly, a single determination of blood toluene concentration in 14 workers at the end of a shift was made. Toluene blood concentrations ranged from $2 \cdot 0$ to $26.0 \mathrm{mg} / 1 .^{6}$

\section{CONTROL GROUP}

The control group consisted of 46 persons ( 23 men, 23 women; mean age 36 years (range 22-54 years)) who met the same inclusion criteria as the exposed group and also had had no relevant exposure to any neurotoxic agent.

Table 2 summarises self estimated attitude of controls to alcohol intake. 
Table 1 Distribution of the exposed group into subgroups according to duration of exposure

\begin{tabular}{lllc}
\hline & \multicolumn{4}{l}{ Duration of exposure $(y)$} & $\geqslant 25$ \\
\cline { 2 - 4 } & $<5$ & $5-24$ & 6 \\
\hline $\begin{array}{l}\text { No of subjects } \\
\%\end{array}$ & 28 & 20 & 11 \\
\hline
\end{tabular}

Table 2 Ethanol intake in control and exposed groups

\begin{tabular}{|c|c|c|c|}
\hline & \multicolumn{2}{|c|}{ Mean daily ethanol intake } & $>50 \mathrm{~g}$ \\
\hline & No $(\%)$ & No $(\%)$ & No $(\%)$ \\
\hline $\begin{array}{l}\text { Exposed group }(n=54) \\
\text { Control group }(n=46)\end{array}$ & $\begin{array}{l}18(33) \\
42(91)\end{array}$ & $\begin{array}{c}13(24) \\
1(2)\end{array}$ & $\begin{array}{c}23(43) \\
3(7)\end{array}$ \\
\hline
\end{tabular}

\section{METHOD OF VEP EXAMINATIONS}

The VEP was examined with Neuromatic 2000 (DISA) apparatus. We used monocular full field checkerboard stimulation, frequency of pattern reversal $1.5 \mathrm{~Hz}$, stimulus field size $12^{\circ} \times 9^{\circ}$, check size $1^{\circ}$, mean luminance of TV screen $20 \mathrm{~cd} / \mathrm{m}^{2}$, and contrast between light and dark checks $69 \%$. Biological activity was recorded from montage $\mathrm{O}_{2}$ to $F_{z}$, high pass filter of amplifier $1 \mathrm{~Hz}$, low pass filter $100 \mathrm{~Hz}$, sweep duration $300 \mathrm{~ms}$. A total of $2 \times 200$ individual responses was averaged.

Figure 1 shows an example of a normal VEP. Parameters of the evoked response evaluated were reproducibility of VEPs at repeated examination of the same eye and ability to differentiate all three main components of the evoked complex, its shape, latency of waves N1, P1, and N2, and amplitudes N1P1 and P1N2.

For the purpose of individual evaluation three criteria of abnormality were chosen: (1) absence of an evoked response that could not be explained technically, (2) prolonged $P 1$ wave latency above the upper limit of the $95 \%$ reference range of our laboratory norm (117 msec), and (3) increased difference of P1 wave latency at stimulation of the right and left eye above the upper limit of our norm $(6 \mathrm{~ms})$.

\section{STATISTICAL ANALYSIS}

Comparison of the frequency of abnormal VEP between the control and exposed groups was by Student's $t$ test. For comparison of VEP latency and amplitude between the control and exposed groups the non-parametric Wilcoxon-White test was applied. Dependence of the frequency of abnormal VEP on certain factors was assessed with the trend test. ${ }^{7}$ Association between results of VEP and other measurements was evaluated with Fisher's exact test. The results of the first and second VEP examination were compared by the McNemar test and kappa statistics. ${ }^{8}$

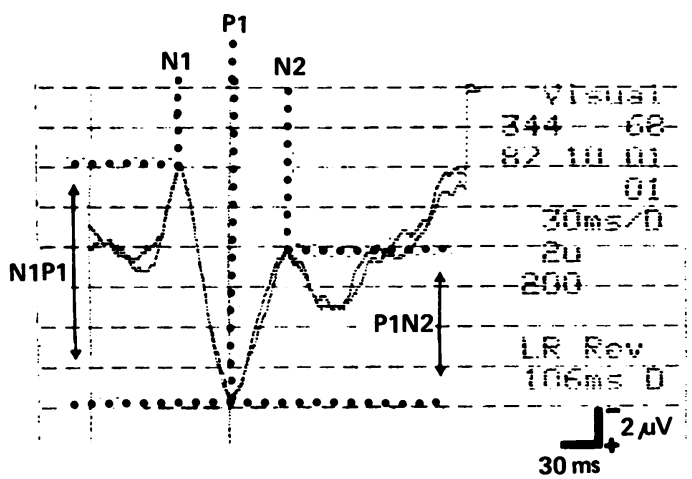

Figure 1 Example of a normal VEP curve. Nomenclature of individual waves and the way of measuring the amplitude are shown.

\section{Results}

EVALUATION AT GROUP LEVEL

Table 3 presents a comparison of the frequency of VEPs with reduced reproducibility, with absence of some waves, or atypical shape of evoked complex, or both, and comparison of the mean latencies of waves $\mathrm{N} 1, \mathrm{P} 1$, and $\mathrm{N} 2$ and of amplitudes N1P1 and P1N2 between the exposed and control groups.

Responses with reduced reproducibility, or with absence of some waves, or both were significantly more frequent in the exposed group than in the controls. The mean latency of Pl waves in the exposed group was prolonged $(p<0.05)$ and the amplitudes N1P1 and P1N2 were decreased $(\mathrm{p}<0.01)$.

\section{EVALUATION AT INDIVIDUAL LEVEL}

One or more of the criteria of abnormality of VEPs were fulfilled in 13 workers ( $24 \%$ ). Evoked response was absent in one worker, latency of the P1 wave was longer than $117 \mathrm{~ms}$ in 12 workers (maximum value $157 \mathrm{~ms}$ ), and the interocular difference of $P 1$ wave latencies was greater than $6 \mathrm{~ms}$ in three workers (maximum value $26 \mathrm{~ms}$ ).

Table 4 compares subgroups with normal and abnormal VEPs. Workers with abnormal VEPs differed from those with normal VEPs by having a greater mean age, longer mean duration of exposure, and a greater per cent of subjects with an estimated intake of ethanol of more than $50 \mathrm{~g}$ daily.

Table 5 shows the frequency of abnormal VEPs in subgroups formed according to duration of exposure. The frequency significantly increased with prolonged duration of exposure $(p<0.001)$.

A similar increasing trend in frequency of abnormal VEPs was found in subgroups formed according to the degree of alcohol usage ( $p<0.01$; table 6$)$. On the other hand no significant correlation between the duration of exposure and degree of alcohol intake was found (table 7). 
Table 3 Comparison of parameters of VEP in control and exposed groups

\begin{tabular}{|c|c|c|c|}
\hline \multirow[b]{2}{*}{ Parameter } & \multicolumn{2}{|l|}{ Group } & \multirow{2}{*}{$\begin{array}{l}\text { Statistical significance } \\
\text { of difference }\end{array}$} \\
\hline & Control $(n=46)$ & Exposed $(n=54)$ & \\
\hline $\begin{array}{l}\text { Reduced reproducibility } \\
\text { Incomplete differentiation } \\
\text { Atypical shape } \\
\text { Latency N1 (ms) } \\
\text { Latency PP1 }(\mathrm{ms}) \\
\text { Latency N2 (ms) } \\
\text { Amplitude N1P1 }(\mu \mathrm{V}) \\
\text { Amplitude P1N2 }(\mu \mathrm{V})\end{array}$ & $\begin{array}{c}4 \cdot 3 \% \\
4 \cdot 3 \% \\
10 \cdot 8 \% \\
75(5 \cdot 8)^{\star} \\
105(6 \cdot 0) \\
139(10 \cdot 6) \\
6 \cdot 8(1 \cdot 5) \\
7 \cdot 1(1 \cdot 5)\end{array}$ & $\begin{array}{c}20 \cdot 2 \% \\
25 \cdot 8 \% \\
17 \cdot 1 \% \\
79(12 \cdot 6) \\
110(13 \cdot 3) \\
146(20 \cdot 6) \\
4 \cdot 3(2 \cdot 3) \\
4 \cdot 8(2 \cdot 2)\end{array}$ & $\begin{array}{l}\mathrm{p}<0.01 \\
\mathrm{p}<0.01 \\
\mathrm{NS} \\
\text { NS } \\
\mathrm{p}<0.05 \\
\text { NS } \\
\mathrm{p}<0.01 \\
\mathrm{p}<0.01\end{array}$ \\
\hline
\end{tabular}

*Latencies and amplitudes are presented as means with standard deviation in parentheses.

NS $=$ Statistically non-significant.

Table 4 Comparison of subgroups of exposed workers with normal VEP result

\begin{tabular}{|c|c|c|c|}
\hline \multirow[b]{2}{*}{ Parameter } & \multicolumn{2}{|l|}{$V E P$ result } & \multirow{2}{*}{$\begin{array}{l}\text { Statistical significance } \\
\text { of difference }\end{array}$} \\
\hline & Normal $(n=41)$ & Abnormal $(n=13)$ & \\
\hline $\begin{array}{l}\text { Age }(y) \\
\text { Duration of exposure (y) } \\
\% \text { Of workers who drank more than } 50 \mathrm{~g} \text { alcohol daily }\end{array}$ & $\begin{array}{l}36 \cdot 5(9 \cdot 4) \\
7 \cdot 8(8 \cdot 9) \\
34\end{array}$ & $\begin{array}{l}43 \cdot 5(10 \cdot 4) \\
17 \cdot 7(9 \cdot 6) \\
69\end{array}$ & $\begin{array}{l}p<0.05 \\
p<0.01 \\
p<0.05\end{array}$ \\
\hline
\end{tabular}

Age and duration of exposure are presented as means with standard deviations in parentheses.

Table 5 Frequency of abnormal VEP findings in subgroups of exposed group formed according to duration of exposure

\begin{tabular}{lll}
\hline Duration of exposure (y) & $\begin{array}{l}\text { No of } \\
\text { subjects }\end{array}$ & Abnormal VEP \\
\hline$<5$ & 28 & $2(7)$ \\
$5-24$ & 20 & $8(40)$ \\
$\geqslant 25$ & 6 & $3(50)$ \\
\hline
\end{tabular}

Table 6 Frequency of abnormal VEP findings in subgroups of exposed group formed according to alcohol intake

\begin{tabular}{lll}
\hline Ethanol intake ( $g$ per day) & $\begin{array}{l}\text { No of } \\
\text { subjects }\end{array}$ & Abnormal VEP \\
\hline$<25$ & 18 & $1(6)$ \\
$25-50$ & 13 & $3(23)$ \\
$>50$ & 23 & $9(39)$ \\
\hline
\end{tabular}

Table 7 Workers with consumption of ethanol over $50 \mathrm{~g}$ daily in subgroups formed according to duration of exposure

\begin{tabular}{lll}
\hline Duration of exposure $(y)$ & $\begin{array}{l}\text { No of } \\
\text { subjects }\end{array}$ & $\begin{array}{l}\text { Users of ethanol } \\
\text { over } 50 \mathrm{~g} \text { daily }\end{array}$ \\
\cline { 2 - 3 } & No $(\%)$ \\
\hline $5-24$ & 28 & $11(39)$ \\
$\geqslant 25$ & 20 & $10(50)$ \\
& 6 & $2(33)$ \\
\hline
\end{tabular}

Table 8 Association between VEP and EEG results

\begin{tabular}{lll}
\hline & $V E P$ & \\
\cline { 2 - 3 } EEG & Normal & Abnormal \\
\hline Normal & 16 & 6 \\
Abnormal & 6 & 2 \\
\hline
\end{tabular}

$p=0.64$, Fisher's exact test.

Table 9 Association between VEP and EMG results

\begin{tabular}{lll}
\hline & VEP & \\
\cline { 2 - 3 } EMG & Normal & Abnormal \\
\hline Normal & 16 & 5 \\
Abnormal & 4 & 1 \\
\hline $\mathrm{p}=0.67$, Fisher's exact test. & &
\end{tabular}

Table 10 Comparison of results of first and second VEP results

\begin{tabular}{lll}
\hline \multirow{2}{*}{ First VEP examination } & \multicolumn{2}{l}{ Second VEP examination } \\
\cline { 2 - 3 } & Normal & Abnormal \\
\hline Normal & 28 & 2 \\
Abnormal & 3 & 5 \\
\hline$\gamma^{2}=0.166$, kappa $=0.4 ;$ NS. & &
\end{tabular}




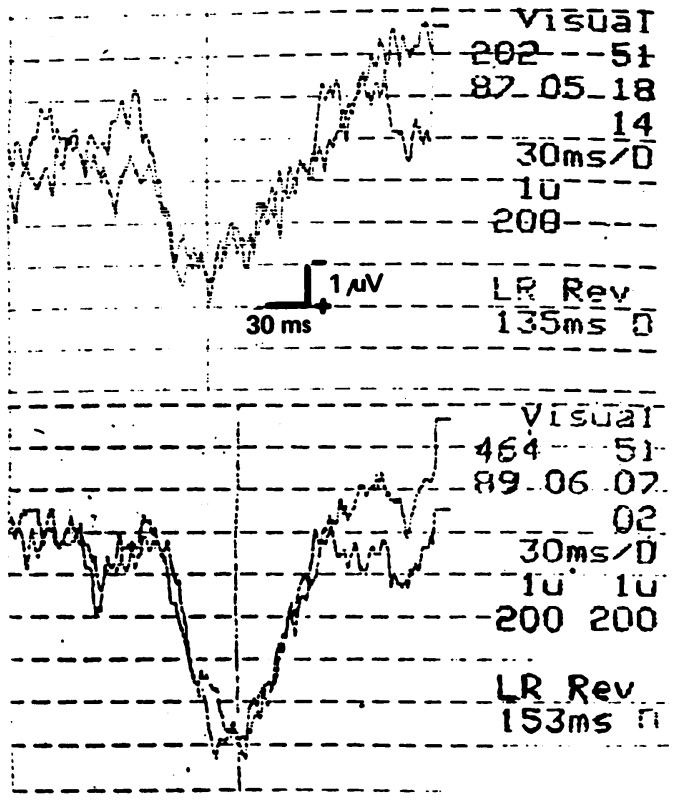

Figure 2 Example of an abnormal VEP curve. Worker, aged 36,14 years of exposure to toluene, $5 / 5$ bilateral vision. Prolonged latency of the evoked complex in the first measurement (upper curve) and in the measurement after two years (lower curve).

Electroencephalograms (EEGs) were recorded in 30 exposed workers. There was no statistically significant association between EEGs and VEPs (table 8).

Electromyograms (EMGs) were examined in 26 exposed workers. The results of EMGs were not significantly associated with those of VEPs (table 9).

\section{VEP RE-EXAMINATION}

A VEP examination was carried out on 42 of the workers $(78 \%)$ after an interval of two years. Thirty eight of them continued their work in the same plant and four had left.

Table 10 compares the results of the first and second examination for those workers who continued their job. The difference between the two examinations was non-significant. The value of kappa statistic indicates that the agreement between the two examinations was not accidental.

As an example, fig 2 presents the results of the first and second examination for one worker. Both results are abnormal with prolonged latency of the evoked complex.

Of the four workers who had left their workplace, two of them had normal results in both tests. The other two had abnormal results in the first examination and after two years the results were abnormal again. Their duration of exposure was 20 (second test one year after leaving job) and 41 years (second test 1.5 years after leaving job).

\section{Discussion}

Comparability of our study with others ${ }^{1-5}$ is limited due to differences in the methods used and in exposure. We used checkerboard stimulation, whereas Seppäläinen $e t a l^{1}$ and Elofsson $e t a l^{\beta}$ used flash. Our group were exposed to toluene whereas Seppäläinen et $a l^{1}$ and Chang ${ }^{5}$ examined workers exposed to $\mathrm{n}$-hexane. The workers in the studies of Elofsson $e t a l^{\beta}$ and Denkhaus $e t a l^{4}$ were exposed to a mixture of organic solvents. The intensity of exposure was high in our group, probably the highest of all studies cited.

The pattern of VEP changes observed by us is in agreement with the results of $\mathrm{Chang}^{5}$; we observed a prolonged latency and reduced amplitude of VEP in our exposed group. Denkhaus $e t a l^{4}$ have also described prolongation of latency, especially for early components of VEP (we were unable to confirm this in our study). On the other hand, Elofsson $e t$ a $l^{\beta}$ failed to discern significant changes in latency. Mean amplitude in their exposed group was higher than in controls. Seeber et $a l^{2}$ also described higher amplitude and shortened latency in an exposed group. In these cases, however, exposure was much less than in our study. At low exposure levels the effect of organic solvents on the CNS can be irritating rather than inhibiting ${ }^{9}$ and this may be an explanation for the higher amplitude and shortened latency of VEP.

We found no significant differences in VEP parameters between men and women in the control group. Hence, we assume that the differences between groups were not related to the different composition with respect to sex.

The subgroup of workers with abnormal VEPs differed from that with normal VEPs by having a greater mean age and longer mean duration of exposure. Because we found no age related changes of VEPs over the range of 20 to 60 years in the control group we presume that the basic functional difference between exposed persons with normal and abnormal VEPs consists of duration of exposure. The association between duration of exposure and frequency of abnormal VEPs suggests a possible causal connection between the two phenomena.

We also demonstrated a correlation, however, between the frequency of abnormal VEPs and the degree of alcohol intake. The greater intake of alcohol in toluene exposed workers compared with controls has been already pointed out by Juntunen $e t$ al ${ }^{10}$ and Hänninen $e t ~ a l^{11}$. Juntunen $e t$ al also observed a slight association between intake and level of exposure. We were unable to reproduce this in our study. Whether the frequent use of alcohol in toluene exposed workers is due to preselection of people with this tendency or whether high alcohol intake is a consequence of such work is speculative but this fact must be taken into account when aetiology of VEP changes is considered. 
Results of VEP examination failed to correlate with those of EMG. Decrease of conduction velocity in the nerves of lower extremities, however, correlated significantly with the clinical finding of hyporeflexia or areflexia and this finding correlated again with the degree of alcohol intake. Apparently this is a manifestation of initial ethylic polyneuropathy.

Neither did results of VEP correlate with those of EEG. This indicates that the two methods test different aspects of activity of the CNS. When looking for early signs of central neurotoxicity, therefore, both methods should be applied.

The re-examination after two years demonstrated considerable stability of changes in VEP. This suggests that VEP abnormalities are a manifestation of changes of a stable nature, perhaps structural.

Our results are in agreement with conclusions of other authors that VEP changes can be detected in people exposed to organic solvents for a long time. As we have seen these changes in clinically healthy individuals we assume them to be a manifestation of subclinical deviations in activity of the CNS.

On the basis of our results we can make no final conclusion about the aetiology of these changes in VEP. A possible association with exposure to toluene is indicated by the dose response relation. Similar changes have been described by Cooper $e t a^{12}$ for a different form of toluene exposure-by sniffers. Schaumburg and Spencer demonstrated experimentally that after exposure to another organic solvent, $\mathrm{n}$-hexane, morphological changes in the CNS occur in the structure of the visual pathway. ${ }^{13}$

As well as toluene, participation of other factors must be taken into account, especially chronic consumption of alcohol ${ }^{1415}$ and the person's disposition to the development of neurotoxic impairment.

From the clinical point of view abnormal VEPs can be regarded as an electrophysiological marker of functional disorder of the CNS. Further prospective monitoring of persons with this finding would make it possible in the future to determine its full clinical implications and to estimate whether its presence is prognostically associated with the increased risk of adverse health consequences-for example, with the development of toxic encephalopathy in terms of the so called solvent syndrome described by the Scandinavian authors. ${ }^{16-18}$

We thank Dr M Josifek for his kind help with the statistical evaluation of results and Mrs L Hamsová for skilled technical help.

Requests for reprints to: Dr P Urban CSc, HPNPIHE, Srobárova 48, 10042 Praha 10, ČSSR.

1 Seppäläinen AM, Raitta C, Huuskonen MS. n-Hexane-induced changes in visual evoked potentials and electroretinograms of industrial workers. Electroencephalogr Clin Neurophysiol 1979;47:492-8.

2 Seeber A, Gutewort G, Zeller HJ. Zur Hepatotoxität und Neurotoxizität von Schwefelkohlenstoff, Styren, Toluen und Tetrachloethylen. Forschungsbericht aus dem Zentral-institut fur Arbeitsmedizin der DDR, Berlin. 1980:106-9.

3 Elofsson SA, Gamberale F, Hindmarsh T, et al. Exposure to organic solvents. A cross-sectional epidemiologic investigation on occupationally exposed car and industrial spray painters with special reference to the nervous system. Scand J Work Environ Health 1980;6:239-73.

4 Denkhaus W, Peise H, Konietzko H. Visuell evozierte Potentiale bei langjälösemittelexponierten Arbeitnehmern der Holzindustrie. Abstracts of the IVth International Congress of Industrial Neurology, Prague 1984:3.

5 Chang YC. Neurotoxic effects of $n$-hexane on the human central nervous system: evoked potential abnormalities in n-hexane polyneuropathy. J Neurol Neurosurg Psychiatry 1987;50: 269-74.

6 Frantik E, Beneš V, Hornychová $M$, et al. Comparisons of biological exposure test for toluene with toluene blood concentration in printers. Abstracts of Polish-Czechoslovakian scientific conference on industrial toxicology, Sosnowiec, 1988:5.

7 Pfanzagl J. Allgemeine Methodenlehre der Statistik II. Berlin: Walter de Gruyter and Co, 1966:315.

8 Longstreth WT, Koepsell TD, van Belle G. Clinical neuroepidemiology. I. diagnosis. Arch Neurol 1987;44: 1091-9.

9 World Health Organisaton. Toluene. IPCS environmental health criteria 52. Copenhagen: WHO, 1985:1-146.

10 Juntunen J, Matikainen E, Antti-Poika M, et al. Nervous system effects of long-term occupational exposure to toluene. Acta Neurol Scand 1985;72:512-17.

11 Hänninen H, Antti-Poika M, Savolainen P. Psychological performance, toluene exposure and alcohol consumption in rotogravure printers. Int Arch Occup Environ Health 1987;59:475-83.

12 Cooper $R$, Newton $P$, Reed $M$. Neurophysiological signs of brain damage due to glue sniffing. Electroencephalogr Clin Neurophysiol 1985;60:23-6.

13 Schaumburg HH, Spencer PS. Environmental hydrocarbons produce degeneration in cat hypothalamus and optic tract. Science 1978;199:199-200.

14 Chan YW, McLeod JG, Tuck RR, et al. Visual evoked responses in chronic alcoholics. J Neurol Neurosurg Psychiatry 1986;49:945-50.

15 Diamond I. Studies of acute and chronic effects of ethanol on early evoked potentials. Alcohol 1987;4:255-6.

16 Antti-Poika M. Prognosis of symptoms in patients with diagnosed chronic organic solvent intoxication. Int Arch Occup Environ Health 1982;51:81-9.

17 Juntunen J. Organic solvent intoxications in occupational neurology. Acta Neurol Scand 1984;69:105-20

18 Vliet van C, Swaen GMH, Slangen JJM, et al. The organic solvent syndrome. A comparison of cases with neuropsychiatric disorders among painters and construction workers. Int Arch Occup Environ Health 1987;59:493-501.

Accepted 14 May 1990. 